\title{
A Modified Chi-square Type Test for Distributional Validity with Applications to Right Censored Reliability and Medical Data
}

\author{
Haitham M. Yousof ${ }^{1}$, Abdullah H. Al-nefaie ${ }^{2}$, Khaoula Aidi ${ }^{3}$, \\ M. Masoom Ali ${ }^{4}$, and Mohamed Ibrahim ${ }^{5, *}$ \\ * Corresponding Author
}

1 Department of Statistics, Mathematics and Insurance, Faculty of Commerce, Benha University, Benha 13518,

Egypt. Email: haitham.yousof@fcom.bu.edu.eg

2.Quantitative Methods Department, School of Business, King Faisal University. Email:

aalnefaie@kfu.edu.sa

3 Laboratory of probability and statistics LaPS, University Badji Mokhtar, Annaba, Algeria. Email: khaoula.aidi@yahoo.fr

4 Department of Mathematical Sciences Ball State University, Muncie, Indiana 47306 USA. Email: mali@bsu.edu

5 Department of Applied, Mathematical and Actuarial Statistics, Faculty of Commerce, Damietta University, Damietta, Egypt. Email: mohamed_ibrahim@du.edu.eg

\begin{abstract}
In this paper, a modified Chi-square goodness-of-fit test called the modified Bagdonavičius-Nikulin goodness-offit test statistic is investigated and the applied for distributional validation under the right censored case. The new modified goodness-of-fit test is presented and applied for the right censored data sets. The algorithm of the censored Barzilai-Borwein is employed via a comprehensive simulation study for assessing validity of the new test. The modified Bagdonavičius-Nikulin test is applied to four real and right censored data sets. A new distribution is compared with many other competitive distributions under the new modified Bagdonavičius-Nikulin goodness-offit test statistic.
\end{abstract}

Key Words: Barzilai-Borwein; Bagdonavičius-Nikulin; Right Censored Validation; Goodness-of-fit Test; Simulation.

\section{Introduction}

Statistical methods for testing the validity of a parametric distribution are in increasing progress. Clearly, the presence of censored observations makes them unsuitable. For treating these problems there were many attempts. First, Habib and Thomas (1986) and Hollander and Pena (1992) proposed a modified version of the Chi-squared test for the randomly censored real data based on the well-known estimators of the Kaplan and Meyer. Then, Galanova (2012) considered some nonparametric modifications for the Anderson-Darling statistic (ADS), Kolmogorov-Smirnov statistic (KSS) and the Cramer-Von-Mises statistic (KVMS) for the accelerate failure distributions. Recently, Bagdonavičius and Nikulin (2011a) presented and applied a new type Chi-squared goodness-of-fit test statistic for the censored data (right case). (see Bagdonavičius and Nikulin (2011b)). The new type Chi-squared goodness-of-fit test statistic of Bagdonavičius-Nikulin (B-N) is applied for the distributional validation under the right censored schemes.

In this work, a new modified type Chi-squared goodness-of-fit test statistic which is established based on the wellknown B-N test is presented and applied accordingly for distributional validation under the exponentiated Rayleigh exponentiated Nadarajah-Haghighi model using the right censored case.

First and for assessing purpose, a comprehensive simulation study under the right censored case via the well-known Barzilai-Borwein (BB) algorithm is performed for assessing and then evaluating the right censorship estimation method. Following Ravi and Gilbert (2009), we generated 10,000 samples with different size ( $n=$ 
$25,50,130,350,500,1000)$ from the exponentiated Rayleigh exponentiated Nadarajah-Haghighi model using the some very carefully selected initial values.

The mean square errors are used for assessing the performance of the censored maximum likelihood. The new modified B-N type test is applied using four right censored real data sets for distributional validity. For related applications to the goodness-of-fit statistic test of B-N and its corresponding modifications, see Mansour et al. (2020a) and Mansour et al. (2020d)). Many other tests are presented and analyzed such as the Nikulin-Rao-Robson goodnessof-fit test statistic and the modified Nikulin-Rao-Robson goodness-of-fit test statistic (see Ibrahim et al. (2019), Goual et al. (2019), Yadav et al. (2020) Goual and Yousof (2020) and Yousof et al. (2021b)).

Recently, Aidi et al. (2021) investigated and studied a novel version of the well-known goodness-of-fit test statistic for a new model called the double Burr X distribution with many applications to right censored real medical and reliability datasets. Yousof et al. (2021a) presented new modified Chi-square type test for the right censored distributional validation with some new characterization results and various estimation methods. Yousof et al. (2021c) introduced new modified Chi-square test for the right the censoring distributional validation under a novel Nadarajah Haghighi model with some new characterization results and different estimation methods. Another new version for the right censored validity under a new Chen model with some applications in reliability and medicine is presented by Ibrahim et al. (2021).

\section{Maximum likelihood estimation in censored data case}

Consider the exponentiated Rayleigh (ER) family (Yousof et al., (2017). Then, for the exponentiated NadarajahHaghighi (ENH) baseline model (Lemonte (2013)), the probability density function (PDF) of the exponentiated Rayleigh exponentiated Nadarajah-Haghighi (ERENH) model can be derived as

$$
\left.f_{\underline{\mathcal{V}}}(x)\right|_{(x \geq 0)}=2 \alpha \beta \gamma \vartheta \frac{(x \vartheta+1)^{\gamma-1} \exp \left\{-\left[\left(1-\zeta_{x ; \gamma, \vartheta}\right)^{-\beta}-1\right]^{-2}\right\}}{\zeta_{x ; \gamma, \vartheta}\left(1-\zeta_{x ; \gamma, \vartheta}\right)^{\beta+1}\left(1-\exp \left\{-\left[\left(1-\zeta_{x ; \gamma, \vartheta}\right)^{-\beta}-1\right]^{-2}\right\}\right)^{1-\alpha}},
$$

where $\underline{\boldsymbol{v}}=(\alpha, \beta, \gamma, \vartheta), \alpha>0, \beta>0, \gamma>0$ are three shape parameters, $\vartheta>0$ is a scale parameter and

$$
\zeta_{x ; \gamma, \vartheta}=\exp \left[1-(x \vartheta+1)^{\gamma}\right]
$$

The survival function $S_{\underline{V}}(x)(\mathrm{SF})$ can be written as

$$
S_{\underline{\underline{v}}}(x)=1-\left(1-\exp \left\{-\left[\left(1-\zeta_{x ; \gamma, \vartheta}\right)^{-\beta}-1\right]^{-2}\right\}\right)^{\alpha}
$$

The hazard rate function (HRF), reversed hazard rate function (RHRF) and cumulative hazard rate function (CHRF) of $X$ can be derived with the well-known relationships. Suppose that $X_{1}, X_{2}, \ldots \ldots, X_{n}$ is a random sample with right censoring from ERENH $(\underline{\mathcal{V}})$ distribution. The observed data

$$
\left.x_{i}\right|_{(i=1,2, . ., n)}=\min \left(X_{i}, C_{i}\right)
$$

are the minimum of the survival time $Z_{i}$ and censoring time $C_{i}$ for each subject in the sample. So, $x_{i}$ can be written in the form $\left(x_{i}, w_{i}\right)_{i=1, \ldots, n}$ where $w_{i}=1$ if $Z_{i}$ is the moment of failure (complete observation) and $w_{i}=0$ if $Z_{i}$ is the moment of censoring. The right censoring is assumed to be non-informative, so the expression of the likelihood function is

$$
l(x, \underline{\mathcal{v}})=\left.\Pi_{i=1}^{n} f_{\underline{\mathcal{v}}}\left(x_{i}\right)^{w_{i}} S_{\underline{\underline{v}}}\left(x_{i}\right)^{1-w_{i}}\right|_{\left(w_{i}=1_{Z_{i}<c_{i}}\right)}
$$

The log-likelihood function of ERENH distribution can be derived as

$$
L_{(\underline{v})}=\sum_{i=1}^{n} w_{i}\left[\begin{array}{c}
\ln (2 \alpha \beta \gamma \vartheta)+(\gamma-1) \ln \left(\vartheta x_{i}-1\right)+(2 \beta-1) \ln \mathcal{W}_{i} \\
-c_{i}-3 \beta \ln \mathcal{W}_{i}-\left(d_{i}\right)^{2}+(\alpha-1) \ln \left(1-\zeta_{d_{i}}\right)
\end{array}\right]
$$


where

$$
-\sum_{i=1}^{n}\left(1-w_{i}\right) \ln \left[1-\left(1-\zeta_{d_{i}}\right)^{\alpha}\right]
$$

$$
\begin{gathered}
\mathcal{W}_{i}=1-\varsigma_{\left[x_{i} ; \gamma, \vartheta\right]}, \\
c_{i}=1-\left(x_{i} \vartheta+1\right)^{\gamma}, \\
\varsigma_{d_{i}}=\exp \left(-d_{i}^{2}\right),
\end{gathered}
$$

and

$$
d_{i}=\frac{\mathcal{W}_{i}^{\beta}}{1-\mathcal{W}_{i}^{\beta}}
$$

The score functions are obtained as follows

$$
\begin{gathered}
\frac{\partial L_{(\underline{\underline{v}})}}{\partial \alpha}=\sum_{i=1}^{n} w_{i}\left[\frac{1}{\alpha}+\ln \left(1-\zeta_{d_{i}}\right)\right]-\sum_{i=1}^{n}\left(1-\mathcal{w}_{i}\right) \frac{\left(1-\zeta_{d_{i}}\right)^{\alpha} \ln \left(1-\zeta_{d_{i}}\right)}{1-\left(1-\zeta_{d_{i}}\right)^{\alpha}} \\
\frac{\partial L_{(\underline{\mathcal{v}})}}{\partial \beta}=\sum_{i=1}^{n} w_{i}\left[\frac{1}{\beta}-\ln \left(\mathcal{W}_{i}\right)-\frac{2 \mathcal{W}_{i}^{2 \beta} \ln \left(\mathcal{W}_{i}\right)}{\left(1-\mathcal{W}_{i}^{\beta}\right)^{3}}+\frac{2(\alpha-1) \mathcal{W}_{i}^{2 \beta} \ln \left(\mathcal{W}_{i}\right) \zeta_{d_{i}}}{\left(1-\mathcal{W}_{i}^{\beta}\right)^{3}\left(1-\zeta_{d_{i}}\right)}\right] \\
-2 \alpha \sum_{i=1}^{n} \frac{\left(1-\mathcal{w}_{i}\right) \mathcal{W}_{i}^{2 \beta} \ln \left(\mathcal{W}_{i}\right) \zeta_{d_{i}}\left(1-\zeta_{d_{i}}\right)^{\alpha-1}}{\left(1-\mathcal{W}_{i}^{\beta}\right)^{3}\left[1-\left(1-\zeta_{d_{i}}\right)^{\alpha}\right]}
\end{gathered}
$$

$$
\begin{aligned}
& \frac{\partial L_{(\underline{\underline{v}})}}{\partial \gamma} \\
& =\sum_{i=1}^{n} w_{i}\left[\begin{array}{c}
\frac{1}{\gamma}+\left(1+\left(1+\vartheta x_{i}\right)^{\gamma}\right) \ln \left(1+\vartheta x_{i}\right)-\frac{(\beta-1)\left(\vartheta x_{i}+1\right)^{\gamma} \ln \left(1+\vartheta x_{i}\right) \exp \left(-c_{i}\right)}{\mathcal{W}_{i}} \\
-\frac{2 \beta\left(\vartheta x_{i}+1\right)^{\gamma} \ln \left(1+\vartheta x_{i}\right) \exp \left(-c_{i}\right) d_{i}^{2}}{\mathcal{W}_{i}\left(1-\mathcal{W}_{i}^{\beta}\right)}+\frac{2(\alpha-1) \beta\left(\vartheta x_{i}+1\right)^{\gamma} \ln \left(1+\vartheta x_{i}\right) \exp \left(-c_{i}\right) d_{i}^{2} \zeta_{d_{i}}}{\mathcal{W}_{i}\left(1-\mathcal{W}_{i}^{\beta}\right)\left(1-\zeta_{d_{i}}\right)}
\end{array}\right] \\
& -2 \alpha \beta \sum_{i=1}^{n} \frac{\left(1-\mathcal{w}_{i}\right)\left(\vartheta x_{i}+1\right)^{\gamma} \ln \left(1+\vartheta x_{i}\right) \exp \left(-c_{i}\right) d_{i}^{2} \zeta_{d_{i}}\left(1-\zeta_{d_{i}}\right)^{\alpha-1}}{\mathcal{W}_{i}\left(1-\mathcal{W}_{i}^{\beta}\right)\left[1-\left(1-\zeta_{d_{i}}\right)^{\alpha}\right]}
\end{aligned}
$$

and

$$
\begin{aligned}
& \frac{\partial L_{(\underline{\underline{v}})}}{\partial \vartheta}=\sum_{i=1}^{n} w_{i}\left[\begin{array}{c}
\frac{1}{\vartheta}+\frac{(\gamma-1) x_{i}}{1+\vartheta x_{i}}+\gamma x_{i}\left(1+\vartheta x_{i}\right)^{\gamma-1}+\frac{(5 \beta-1) \gamma x_{i} \exp \left(-c_{i}\right)\left(\vartheta x_{i}+1\right)^{\gamma-1}}{\mathcal{W}_{i}} \\
+\frac{2 \beta \gamma x_{i} \exp \left(-c_{i}\right) d_{i}^{2}\left(\vartheta x_{i}+1\right)^{\gamma-1}}{\mathcal{W}_{i}\left(1-\mathcal{W}_{i}^{\beta}\right)}-\frac{2(\alpha-1) \beta \gamma x_{i} \exp \left(-c_{i}\right) d_{i}^{2} \zeta_{d_{i}}\left(\vartheta x_{i}+1\right)^{\gamma-1}}{\mathcal{W}_{i}\left(1-\mathcal{W}_{i}^{\beta}\right)\left(1-\zeta_{d_{i}}\right)}
\end{array}\right] \\
& -2 \alpha \gamma \beta \sum_{i=1}^{n} \frac{\left(1-\mathcal{w}_{i}\right) x_{i} \exp \left(-c_{i}\right) d_{i}^{2} \zeta_{d_{i}}\left(\vartheta x_{i}+1\right)^{\gamma-1}\left(1-\zeta_{d_{i}}\right)^{\alpha-1}}{\mathcal{W}_{i}\left(1-\mathcal{W}_{i}^{\beta}\right)\left[1-\left(1-\zeta_{d_{i}}\right)^{\alpha}\right]} \text {. }
\end{aligned}
$$


Maximum likelihood estimates of the unknown parameters $\alpha, \beta, \gamma$ and $\vartheta$ can be obtained using various techniques, either software R, EM algorithm or Newton Raphson method.

\section{Modified B-N Chi-square type test for right censored data}

In this work, we are interested by the modified Chi-square type test proposed in Bagdonavičius and Nikulin (2011a,b) for parametric models with right censored data. Based on maximum likelihood estimators on non-grouped data, this test statistic is also based on the differences between the numbers of observed failures and the numbers of expected failures in the grouped intervals chosen. For this, random grouping intervals are considered as data functions. The test statistic is defined as follows. Suppose that $Z_{1}, Z_{2}, \ldots, Z_{n}$ is a random sample with right censoring from a parametric model, and a finite time $\tau$. The test statistic is defined as

$$
Y_{n}^{2}=\boldsymbol{Q}+\sum_{j=1}^{n} \frac{1}{U_{j}}\left(U_{j}-\varrho_{j}\right)^{2},
$$

where $U_{j}$ and $\varrho_{j}$ are the observed and the expected numbers of failure in grouping intervals, and $\mathcal{Q}$ is given in Mansour et al. (2020a,b), Abouelmagd et al. (2019a,b), Salah et al. (2020), Goual et al., (2020), Yadav et al., (2020), Goual and Yousof (2020) and Ibrahim et al. (2019 and 2021) with details. The limits $p_{j}$ of $k$ random grouping intervals $I_{j}=$ $\left[p_{j-1}, p_{j}[\right.$ are chosen such as the expected failure times to fall into these intervals are the same for each $j=1, \ldots, k-$ 1 . The estimated $\hat{p}_{j}$ is defined by

$$
\hat{p}_{j}=\mathrm{H}^{-1}\left\{\frac{1}{n-i+1}\left[E_{j}-\sum_{j=1}^{i-1} H_{\underline{v}}\left(x_{\ell}\right)\right], \underline{\hat{v}}\right\}, j=1,2, \ldots, k,
$$

where $H_{\underline{v}}\left(x_{\ell}\right)$ is the CHRF of our new distribution. This test statistic $Y_{n}^{2}$ follows a Chi-square distribution. Suppose that we have a random sample, $Z_{1}, Z_{2}, \ldots ., Z_{n}$, which is a right censored sample from ERENH model and a finite time $\tau$. The estimated $\hat{\mathcal{p}}_{\boldsymbol{j}}$ is obtained where $H_{\underline{v}}\left(x_{\ell}\right)$ is the CHRF of the ERENH distribution. To calculate the quadratic form $\mathcal{Q}$ of the statistic $Y_{n}^{2}$, we shall use the estimated matrices $\widehat{W}, \hat{C}$ and the estimated information matrix $\hat{I}$. Therefore, the estimated matrix $\widehat{W}$ can be obtained from $\hat{C}$. The information matrix $\hat{I}$ of the ERENH distribution is also needed in case of the right censoring case.

\section{Simulated censored samples}

In this section we conduct an important simulation study to consolidate our results. For this, $N=10,000$ censored samples with sizes: $n=25,50,130,350,500,1000$ from ERENH distribution are simulated. We generate the simulated samples with various values of parameters. Using R software and BB algorithm (Ravi and Gilbert (2009)), simulated maximum likelihood estimators (MSMLEs) and their mean square errors (MSEs) are calculated and given in Table 1. As seen in these results, MSEs are convergent.

Table 1: MSMLEs of $\alpha, \beta, \gamma, \vartheta$ and theirs MSEs.

\begin{tabular}{ccccc}
\hline $\mathrm{N}=10.000 \& \mathrm{n} \downarrow$ & & & & \\
& $\alpha=2$ & $\beta=1.5$ & $\gamma=2$ & $\vartheta=0.9$ \\
\hline 25 & 1.9468 & 1.5176 & 2.0133 & 0.9102 \\
& $(0.012)$ & $(0.001)$ & $(0.009)$ & $(0.007)$ \\
50 & 1.9557 & 1.5143 & 2.0072 & 0.9078 \\
& $(0.011)$ & $(0.009)$ & $(0.008)$ & $(0.005)$ \\
130 & 1.9668 & 1.5126 & 2.0052 & 0.9043 \\
& $(0.009)$ & $(0.007)$ & $(0.008)$ & $(0.004)$ \\
350 & 1.9787 & 1.5102 & 2.0038 & 0.9022 \\
& $(0.008)$ & $(0.007)$ & $(0.005)$ & $(0.004)$ \\
500 & 1.9816 & 1.5083 & 2.0026 & 0.9017 \\
& $(0.006)$ & $(0.006)$ & $(0.004)$ & $(0.002)$ \\
1000 & 1.9943 & 1.5031 & 2.0013 & 0.9008
\end{tabular}




\begin{tabular}{|c|c|c|c|c|}
\hline & $(0.006)$ & $(0.004)$ & $(0.002)$ & $(0.001)$ \\
\hline & $\alpha=4$ & $\beta=2$ & $\gamma=2.5$ & $\vartheta=5$ \\
\hline \multirow[t]{2}{*}{25} & 3.9715 & 2.0192 & 2.5246 & 4.9618 \\
\hline & (0.009) & $(0.007)$ & $(0.007)$ & (0.008) \\
\hline \multirow[t]{2}{*}{50} & 3.9777 & 2.0177 & 2.5202 & 4.9736 \\
\hline & (0.006) & $(0.007)$ & $(0.006)$ & $(0.007)$ \\
\hline \multirow[t]{2}{*}{130} & 3.9804 & 2.0156 & 2.5197 & 4.9782 \\
\hline & (0.004) & (0.006) & $(0.005)$ & $(0.006)$ \\
\hline \multirow[t]{2}{*}{350} & 3.9873 & 2.0124 & 2.5136 & 4.9824 \\
\hline & (0.004) & $(0.005)$ & (0.004) & (0.004) \\
\hline \multirow[t]{2}{*}{500} & 3.9898 & 2.0091 & 2.5089 & 4.9873 \\
\hline & $(0.003)$ & $(0.004)$ & (0.003) & (0.004) \\
\hline \multirow[t]{3}{*}{1000} & 3.9937 & 2.0026 & 2.5016 & 4.9912 \\
\hline & $(0.001)$ & $(0.003)$ & $(0.002)$ & $(0.003)$ \\
\hline & $\alpha=0.8$ & $\beta=1$ & $\gamma=0.05$ & $\vartheta=0.35$ \\
\hline \multirow[t]{2}{*}{25} & 0.8208 & 0.9516 & 0.0519 & 0.3446 \\
\hline & (0.009) & $(0.011)$ & $(0.004)$ & $(0.006)$ \\
\hline \multirow[t]{2}{*}{50} & 0.8196 & 0.9696 & 0.0516 & 0.3472 \\
\hline & $(0.007)$ & (0.009) & $(0.003)$ & $(0.005)$ \\
\hline \multirow{2}{*}{130} & 0.8135 & 0.9754 & 0.0513 & 0.3479 \\
\hline & $(0.005)$ & (0.009) & $(0.003)$ & $(0.0034)$ \\
\hline \multirow[t]{2}{*}{350} & 0.8112 & 0.9836 & 0.0509 & 0.3483 \\
\hline & (0.004) & $(0.008)$ & $(0.002)$ & $(0.003)$ \\
\hline \multirow[t]{2}{*}{500} & 0.8086 & 0.9873 & 0.0503 & 0.3491 \\
\hline & $(0.002)$ & $(0.0063)$ & $(0.0012)$ & $(0.002)$ \\
\hline \multirow[t]{3}{*}{1000} & 0.8013 & 0.9926 & 0.0501 & 0.3497 \\
\hline & $(0.001)$ & $(0.005)$ & $(0.0004)$ & $(0.0011)$ \\
\hline & $\alpha=0.5$ & $\beta=1.2$ & $\gamma=0.1$ & $\vartheta=0.75$ \\
\hline \multirow[t]{2}{*}{25} & 0.5197 & 1.1703 & 0.1097 & 0.7527 \\
\hline & $(0.007)$ & $(0.007)$ & $(0.005)$ & (0.004) \\
\hline \multirow[t]{2}{*}{50} & 0.5146 & 1.1786 & 0.1056 & 0.7522 \\
\hline & (0.006) & $(0.006)$ & (0.004) & (0.004) \\
\hline \multirow[t]{2}{*}{130} & 0.5126 & 1.1816 & 0.1023 & 0.7518 \\
\hline & (0.005) & $(0.006)$ & $(0.0035)$ & $(0.003)$ \\
\hline \multirow[t]{2}{*}{350} & 0.5092 & 1.1883 & 0.1015 & 0.7512 \\
\hline & (0.004) & $(0.0043)$ & $(0.0021)$ & $(0.003)$ \\
\hline \multirow[t]{2}{*}{500} & 0.5076 & 1.1924 & 0.1008 & 0.7509 \\
\hline & $(0.0025)$ & $(0.003)$ & $(0.0013)$ & $(0.002)$ \\
\hline \multirow{2}{*}{1000} & 0.5010 & 1.1993 & 0.1002 & 0.7503 \\
\hline & $(0.001)$ & $(0.0021)$ & $(0.0005)$ & $(0.0006)$ \\
\hline
\end{tabular}

\section{Four right censored data applications}

The new modified B-N test for validation under the right censored data is applied for four real and right censored data sets.

Data set I (survival data):

$1,1,2,11,14,22,22,24,25,26,28,30^{*}, 30^{*}, 31^{*}, 31^{*}, 32,33^{*}, 33^{*}, 34^{*}, 35,35^{*}, 35^{*}, 36^{*}, 37^{*}, 39^{*}, 40$. ( $^{*}$ indicates the censorship) (see John et al., (1997)).

Data set II (acute myeloid leukemia data):

$0.030,0.493,0.855,1.184,1.283,1.480,1.776,2.138,2.5,2.763,2.993,3.224,3.421,4.178,4.441^{*}, 5.691,5.855^{*}$ ,6.941*, 6.941, 7.993*, 8.882, 8.882, 9.145*, 11.480, 11.513, 12.105*, 12.796, 12.993*, 13.849*, 16.612*, 17.138*, 20.066, 20.329*, 22.368*, 26.776*, 28.717*, 28.717* 32.928*, 33.783*, 34.211* , 34.770*, 39.539* , 41.118*, 
45.033* , 46.053* , 46.941*, 48.289*, 57.401*, 58.322*, 60.625* (see John et al., (1997)).

Data set III (reliability data):

$26.8^{*}, 29.6^{*}, 33.4^{*}, 35^{*}, 36.3,40^{*}, 41.7,41.9^{*}, 42.5^{*}, 43.9,49.9,50.1,50.8,51.9,52.1,52.3,52.3,52.4,52.6$, 52.7, 53.1, 53.6, 53.6, 53.9, 53.9, 54.1, 54.6, 54.8, 54.8, 55.1, 55.4, 55.9, 56, 56.1, 56.5, 56.9, 57.1, 57.1, 57.3, 57.7, 57.8, 58.1, 58.9, 59, 59.1, 59.6, 60.4, 60.7 (see Crowder et al., (1991)).

Data set IV (breast cancer data):

$19,25,30,34,37,46,47,51,56,57,61,66,67,74,78,86,122^{*}, 123^{*}, 130^{*}, 130^{*}, 133^{*}, 134^{*}, 136^{*}, 141^{*}$, $143^{*}, 148^{*}, 151^{*}, 152^{*}, 153^{*}, 154^{*}, 156^{*}, 162^{*}, 164^{*}, 165^{*}, 182^{*}, 189^{*}$ (see see John et al., (1997)).

We will compare ERENH with the Rayleigh Nadarajah-Haghighi, the odd Lindley Nadarajah-Haghighi distribution (OLNH) (Yousof et al., (2017)), Proportional reversed hazard rate Nadarajah-Haghighi (PRHRNH), exponentiated Weibull Nadarajah-Haghighi, the Gamma Nadarajah-Haghighi (GaNH) (Ortega et al., (2015)), Marshall-Olkin Nadarajah-Haghighi (MONH) (Lemonte et al., (2016)), exponentiated Nadarajah-Haghighi (ENH) (Lemonte (2013)), beta Nadarajah-Haghighi (BNH ) (Dias et al., (2018)) and the standard Nadarajah-Haghighi distribution (Nadarajah and Haghighi (2011)). Other Nadarajah-Haghighi extension can be used in comparison such as: the odd Lindley Nadarajah- Haghighi distribution (Yousof and Korkmaz (2017)), the extended exponentiated Nadarajah-Haghighi model (2018), the Burr X Nadarajah Haghighi distribution (Elsayed and Yousof (2019)), the odd Nadarajah-Haghighi family (Nascimento et al. (2019)) and the generalized odd Log-logistic Nadarajah Haghighi distribution (Ibrahim (2019)).

The first data set has reported survival data on 26 psychiatric inpatients admitted to the university of Iowa hospitals during the years 1935-1948. This sample is part of a larger study of psychiatric Inpatients discussed by Tsuang and Woolson (1977). Data for each patient consists of age, sex, number of years of follow-up (years from admission to death or censoring) and patient status at the follow-up time.

The second data set consists of sample data from 50 patients with acute myeloid leukemia, reported to the International Register of Bone Marrow Transplants. These patients had an allogeneic bone marrow transplant where the Histocompatibility Leukocyte Antigen (HLA) homolog marrow was used to rebuild their immune systems.

The third data set, we apply the results obtained from this study to real data established from reliability. In an experiment to obtain information on the strength of a certain type of braided cord after the weather, the forces of 48 pieces of cord having resisted for a determined time were studied.

Fourth data set consists of a study designed to determine if female breast cancer patients, originally classified as lymph node negative by standard light microscopy (SLM), could be more accurately classified by immunohistochemical (IH) examination of their lymph nodes with an anti-cytokeratin monoclonal antibody cocktail, identical sections of lymph nodes were sequentially examined by SLM and IH. The significance of this study is that $16 \%$ of patients with negative axillary lymph nodes, by standard pathological examination, develop recurrent disease within 10 years. Forty-five female breast-cancer patients with negative axillary lymph nodes and a minimum 10-year follow-up were selected from The Ohio State University Hospitals Cancer Registry. Of the 45 patients, 9 were immunoperoxidase positive, and the remaining 36 remained negative. This data represents times to death (in months) for breast cancer patients with different immunohistochemical responses.

Table 2 gives the estimated parameters and values of $\mathrm{Y}^{2}$ against $\chi_{h}^{2} \mid \varepsilon=0.05$ for the four data sets. Then the critical values are $\chi_{5}^{2}=11.0705$ for $k=5$, and $\chi_{4}^{2}=9,4877$ for $k=4$. According to the results obtained in Table 2, these four data sets can be fitted by several distributions where $\mathrm{Y}^{2}=7.963$ (for data set I), 8.146 (for data set II), 9.677 (for data set III) and 7.129 (for data set IV). Table 3 gives the $\mathrm{Y}^{2}$ values for all completive Nadarajah-Haghighi extensions. According to the results obtained in Table 3, the ERENH has the lowest value of the goodness-of-fit statistic $Y^{2}=7.963$ (for data set I), 8.146 (for data set II), 9.677 (for data set III) and 7.129 (for data set IV). 
Table 2: The values of $\mathrm{Y}^{2}$ for the four data sets.

\begin{tabular}{ccccc}
\hline Parameters $\downarrow$ \& Data $\rightarrow$ & I & II & III & IV \\
\hline$\alpha$ & 1.317 & 2.069 & 4.163 & 1.847 \\
$\beta$ & 2.614 & 0.911 & 1.365 & 0.820 \\
$\gamma$ & 0.987 & 1.041 & 2.394 & 1.528 \\
$\vartheta$ & 1.037 & 0.942 & 3.563 & 2.347 \\
$k$ & 4 & 5 & 5 & 4 \\
$Y^{2}$ & 7.963 & 8.146 & 9.677 & 7.129 \\
$\chi_{k}^{2} \mid \varepsilon=0.05$ & $\chi_{4}^{2}=9,4877$ & $\chi_{5}^{2}=11.0705$ & $\chi_{5}^{2}=11.0705$ & $\chi_{4}^{2}=9,4877$ \\
Decision & Accept $H_{0}$ & Accept $H_{0}$ & Accept $H_{0}$ & Accept $H_{0}$ \\
Rank & 2 & 3 & 4 & 1 \\
\hline
\end{tabular}

Table 3: $Y^{2}$ values for all competing models.

\begin{tabular}{ccccc}
\hline $\begin{array}{c}\text { Data } \rightarrow \\
\text { Model } \downarrow \text { \& } \mathrm{Y}^{2} \rightarrow\end{array}$ & I & II & III & IV \\
\cline { 2 - 5 } ERENH & $\mathbf{7 . 9 6 3}$ & $\mathbf{8 . 1 7 6}$ & $\mathbf{9 . 6 7 7}$ & $\mathbf{7 . 1 2 9}$ \\
RENH & 8.125 & 8.202 & 9.823 & 7.262 \\
RNH & 8.335 & 8.347 & 9.691 & 8.168 \\
NH & 8.264 & 8.211 & 9.762 & 7.341 \\
GaNH & 8.468 & 8.568 & 10.12 & 7.412 \\
OLNH & 8.033 & 8.219 & 9.730 & 7.621 \\
PRHRNH & 8.535 & 8.861 & 9.831 & 7.736 \\
ENH & 8.174 & 8.227 & 9.916 & 7.827 \\
BNH & 8.966 & 8.778 & 9.991 & 8.236 \\
\hline
\end{tabular}

\section{Conclusions}

A modified type statistic B-N goodness-of-fit test is investigated and applied for distributional validation under the right censored case. The new modified goodness-of-fit test is presented based on the B-N Chi-square goodness-of-fit test. The algorithm of the censored Barzilai-Borwein is employed via a comprehensive simulation study for assessing the new test. The modified B-N test is applied to four real and right censored data sets. A new distribution called exponentiated Rayleigh exponentiated Nadarajah-Haghighi distribution is compared with many other competitive Nadarajah-Haghighi extensions under the new modified B-N goodness-of-fit test statistic. The test can be used in validity studies of medical and reliability censored real data sets.

As a future potential work, many bivariate versions of the ERENH model could be introduced and studied (see AlBabtain et al. (2020a,b), Elgohari and Yousof (2020a,b) and Shehata and Yousof (2021)).

\section{References}

1. Abouelmagd, T. H. M., Hamed, M. S., Handique, L., Goual, H., Ali, M. M., Yousof, H. M. and Korkmaz, M. C. (2019a). A new class of distributions based on the zero truncated Poisson distribution with properties and applications, 12(3), 152-164.

2. Abouelmagda, T. H. M., Hameda, M. S., Hamedanib, G. G., Alic, M. M., Goual, H., Korkmaze, M. C. and Yousof, H. M. (2019b). The zero truncated Poisson Burr X family of distributions with properties, characterizations, applications, and valida-tion test. Journal of Nonlinear Sciences and Applications, 12(5), 314-336. 
1. Aidi, K., Butt, N. S., Ali, M. M., Ibrahim, M., Yousof, H. M. and Shehata, W. A. M. (2021). A Modified Chisquare Type Test Statistic for the Double Burr X Model with Applications to Right Censored Medical and Reliability Data. Pakistan Journal of Statistics and Operation Research, 17(3), 615-623.

3. Al-Babtain, A. A., Elbatal, I. and Yousof, H. M. (2020a). A new three parameter Fréchet model with mathematical properties and applications. Journal of Taibah University for Science, 14(1), 265-278.

4. Al-babtain, A. A., Elbatal, I. and Yousof, H. M. (2020b). A New Flexible Three-Parameter Model: Properties, Clayton Copula, and Modeling Real Data. Symmetry, 12(3), 440.

5. Alizadeh, M., Rasekhi, M., Yousof, H. M., Ramires, T. G. and Hamedani G. G. (2018). Extended exponentiated Nadarajah-Haghighi model: mathematical properties, characterizations and applications. Studia Scientiarum Mathematicarum Hungarica, 55, 498-522.

6. Bagdonavičius, V.; Nikulin, M. (2011a). Chi-squared Goodness-of-fit test for right censored Data. Int. J. Appl. Math. Stat., 24, 30-50.

7. Bagdonavičius, V.; Nikulin, M. (2011b). Chi-squared tests for general composite hypotheses from censored samples Comptes Rendus de lácadémie des Sciences de Paris. Mathématiques, 349, 219-223.

8. Crowder, M. J., Kimber A. C., Smith R. L and Sweeting, T. J. (1991). Statistical analysis of reliability data, CHAPMAN \&HALL/CRC

9. Dias, C. R. B., Alizadeh, M. and Cordeiro, G. M. (2018). The beta Nadarajah-Haghighi distribution. Hacettepe Journal of Mathematics and Statistics, 47, 13021323.

10. Elgohari, H. and Yousof, H. M. (2020a). A Generalization of Lomax Distribution with Properties, Copula and Real Data Applications. Pakistan Journal of Statistics and Operation Research, 16(4), 697711.

11. Elgohari, H. and Yousof, H. M. (2020b). New Extension of Weibull Distribution: Copula, Mathematical Properties and Data Modeling. Statistics, Optimization \& Information Computing, 8(4), 972-993.

12. Elsayed, H. A. H. and Yousof, H. M. (2019). The Burr X Nadarajah Haghighi distribution: statistical properties and application to the exceedances of flood peaks data. Journal of Mathematics and Statistics, 15, 146-157.

13. Galanova, N.; Lemeshko, B.Y.; Chimitova, E.V. (2012). Using Nonparametric Goodness-of-Fit Tests to Validate Accelerated Failure Time Models. Optoelectron. Instrum. Data Process, 48, 580-592.

14. Goual, H. and Yousof, H. M. (2020). Validation of Burr XII inverse Rayleigh model via a modified Chi-squared goodness-of-fit test. Journal of Applied Statistics, 47(3), 393-423.

15. Goual, H., Yousof, H. M. and Ali, M. M. (2019). Validation of the odd Lindley exponentiated exponential by a modified goodness of fit test with applications to censored and complete data. Pakistan Journal of Statistics and Operation Research, 15(3), 745-771.

16. Goual, H., Yousof, H. M. and Ali, M. M. (2020). Lomax inverse Weibull model: properties, applications, and a modified Chi-squared goodness-of-fit test for validation. Journal of Nonlinear Sciences \& Applications (JNSA), 13(6), 330-353.

17. Habib, M.G.; Thomas, D.R. (1986). Chi-squared goodness-of-fit tests for randomly censored Data. Ann. Stat, 14, $759-765$.

18. Hollander, M.; Pena, E. (1992). Chi-square goodness-of-fit test for randomly censored data. JASA, 87, 458-463.

19. Ibrahim, M. (2020). The generalized odd Log-logistic Nadarajah Haghighi distribution: statistical properties and different methods of estimation. Journal of Applied Probability and Statistics, 15(2), 61-84.

20. Ibrahim, M., Aidi, K., Ali, M. M. and Yousof, H. M. (2021). A Novel Test Statistic for Right Censored Validity under a new Chen extension with Applications in Reliability and Medicine. Annals of Data Science, forthcoming.

21. Ibrahim, M., Altun, E., Goual, H., and Yousof, H. M. (2021). Modified goodness-of-fit type test for censored validation under a new Burr type XII distribution with different methods of estimation and regression modeling. Eurasian Bulletin of Mathematics, 3(3), 162-182.

22. Ibrahim, M., Yadav, A. S., Yousof, H. M., Goual, H. and Hamedani, G. G. (2019). A new extension of Lindley distribution: modified validation test, characterizations and different methods of estimation. Communications for Statistical Applications and Methods, 26(5), 473-495.

23. John, P. Klein, Melvin L. Moeschberger (1997). Survival Analysis: Techniques for Censored and Truncated Data, Statistics for Biology and Health.

24. Lemonte, A. J. (2013). A new exponential-type distribution with constant, decreasing, increasing, upside-down bathtub and bathtub-shaped failure rate function. Computational Statistics and Data Analysis, 62, 149-170.

25. Lemonte, A. J., Cordeiro, G. M. and Moreno--Arenas, G. (2016). A new useful three-parameter extension of the exponential distribution. Statistics, 50, 312-337. 
26. Mansour, M. M., Ibrahim, M., Aidi, K., Shafique Butt, N., Ali, M. M., Yousof, H. M. and Hamed, M. S. (2020a). A New Log-Logistic Lifetime Model with Mathematical Properties, Copula, Modified Goodness-of-Fit Test for Validation and Real Data Modeling. Mathematics, 8(9), 1508.

27. Mansour, M. M., Butt, N. S., Ansari, S. I., Yousof, H. M., Ali, M. M. and Ibrahim, M. (2020b). A new exponentiated Weibull distribution's extension: copula, mathematical properties and applications. Contributions to Mathematics, 1 (2020) 57-66. DOI: 10.47443/cm.2020.0018

28. Mansour, M., Korkmaz, M. Ç., Ali, M. M., Yousof, H. M., Ansari, S. I. and Ibrahim, M. (2020c). A generalization of the exponentiated Weibull model with properties, Copula and application. Eurasian Bulletin of Mathematics, 3(2), 84-102.

29. Mansour, M., Rasekhi, M., Ibrahim, M., Aidi, K., Yousof, H. M. and Elrazik, E. A. (2020d). A New Parametric Life Distribution with Modified Bagdonavičius-Nikulin Goodness-of-Fit Test for Censored Validation, Properties, Applications, and Different Estimation Methods. Entropy, 22(5), 592.

30. Mansour, M., Yousof, H. M., Shehata, W. A. M. and Ibrahim, M. (2020e). A new two parameter Burr XII distribution: properties, copula, different estimation methods and modeling acute bone cancer data. Journal of Nonlinear Science and Applications, 13(5), 223-238.

31. Mansour, M. M., Butt, N. S., Yousof, H. M., Ansari, S. I. and Ibrahim, M. (2020f). A Generalization of Reciprocal Exponential Model: Clayton Copula, Statistical Properties and Modeling Skewed and Symmetric Real Data Sets. Pakistan Journal of Statistics and Operation Research, 16(2), 373-386.

32. Nadarajah, S.and Haghighi, F. (2011). An extension of the exponential distribution. Statistics, 45, 543--558.

33. Ortiga, E. M., Lemonte, A. J., Silva, G. O. and Cordeiro, G. M. (2015). New flexible models generated by gamma random variables for lifetime modeling. Journal of Applied Statistics, 42(10), 2159-2179.

34. Nascimento, A. D., Silva, K. F., Cordeiro, G. M., Alizadeh, M., Yousof, H. M. and Hamedani, G. G. (2019). The odd Nadarajah-Haghighi family of distributions: properties and applications. Studia Scientiarum Mathematicarum Hungarica, 56(2), 185-210.

35. Ravi, V. and Gilbert, P. D. (2009). BB: An R package for solving a large system of nonlinear equations and for optimizing a high-dimensional nonlinear objective function, J. Statist. Software, 32(4).

36. Salah, M. M., El-Morshedy, M., Eliwa, M. S. and Yousof, H. M. (2020). Expanded Fréchet Model: Mathematical Properties, Copula, Different Estimation Methods, Applications and Validation Testing. Mathematics, 8(11), 1949.

37. Shehata, W. A. M. and Yousof, H. M. (2021). The four-parameter exponentiated Weibull model with Copula, properties and real data modeling. Pakistan Journal of Statistics and Operation Research, 17(3), 649-667.

38. Yadav, A. S., Goual, H., Alotaibi, R. M., Ali, M. M. and Yousof, H. M. (2020). Validation of the Topp-LeoneLomax model via a modified Nikulin-Rao-Robson goodness-of-fit test with different methods of estimation. Symmetry, 12(1), 57.

39. Yousof, H. M., Afify, A. Z., Hamedani, G. G. and Aryal, G. (2017). The Burr X generator of distributions for lifetime data. Journal of Statistical Theory and Applications, 16, 288-305.

40. Yousof, H. M., Aidi, K., Hamedani, G. G and Ibrahim, M. (2021a). A new parametric lifetime distribution with modified Chi-square type test for right censored validation, characterizations and different estimation methods. Pakistan Journal of Statistics and Operation Research, 17(2), 399-425.

41. Yousof, H. M., Ali, M. M., Goual, H. and Ibrahim. M. (2021b). A new reciprocal Rayleigh extension: properties, copulas, different methods of estimation and modified right censored test for validation, Statistics in Transition New Series, 23(3), 1-23.

42. Yousof, H. M., Ali, M. M., Hamedani, G. G., Aidi, K. and Ibrahim, M. (2021c). A new lifetime distribution with properties, characterizations, validation testing, different estimation methods. Statistics, Optimization \& Information Computing, forthcoming.

43. Yousof, H. M. and Korkmaz, M. C. (2017). Topp-Leone Nadarajah-Haghighi distribution: mathematical properties and applications, International Journal of Applied Mathematics. Journal of Statisticians: Statistics and Actuarial Sciences, 2, 119-128.

44. Yousof, H. M., Korkmaz, M. C. Hamedani G. G. (2017). The odd Lindley Nadarajah- Haghighi distribution. J. Math. Comput. Sci., 7, 864-882. 